\title{
Enhancement of Ultrahigh Performance Concrete Material Properties with Carbon Nanofiber
}

\author{
Libya Ahmed Sbia, ${ }^{1}$ Amirpasha Peyvandi, ${ }^{2}$ Parviz Soroushian, \\ Jue $\mathrm{Lu}^{3}$ and Anagi M. Balachandra ${ }^{3}$ \\ ${ }^{1}$ Department of Civil and Environmental Engineering, Michigan State University, 3546 Engineering Building, \\ East Lansing, MI 48824-1226, USA \\ ${ }^{2}$ Bridge Engineering Department, HNTB Corporation, 10000 Perkins Rowe, Suite No. 640, Baton Rouge, LA 70810, USA \\ ${ }^{3}$ Metna Co., 1926 Turner Street, Lansing, MI 48906, USA
}

Correspondence should be addressed to Amirpasha Peyvandi; amirpasha.peyvandi@gmail.com

Received 28 January 2014; Revised 23 July 2014; Accepted 28 July 2014; Published 24 August 2014

Academic Editor: John Mander

Copyright (C) 2014 Libya Ahmed Sbia et al. This is an open access article distributed under the Creative Commons Attribution License, which permits unrestricted use, distribution, and reproduction in any medium, provided the original work is properly cited.

\begin{abstract}
Ultrahigh performance concrete (UHPC) realized distinctly high mechanical, impermeability, and durability characteristics by reducing the size and content of capillary pore, refining the microstructure of cement hydrates, and effectively using fiber reinforcement. The dense and fine microstructure of UHPC favor its potential to effectively disperse and interact with nanomaterials, which could complement the reinforcing action of fibers in UHPC. An optimization experimental program was implemented in order to identify the optimum combination of steel fiber and relatively low-cost carbon nanofiber in UHPC. The optimum volume fractions of steel fiber and carbon nanofiber identified for balanced improvement of flexural strength, ductility, energy sorption capacity, impact, and abrasion resistance of UHPC were $1.1 \%$ and $0.04 \%$, respectively. Desired complementary/synergistic actions of nanofibers and steel fibers in UHPC were detected, which were attributed to their reinforcing effects at different scales, and the potential benefits of nanofibers to interfacial bonding and pull-out behavior of fibers in UHPC. Modification techniques which enhanced the hydrophilicity and bonding potential of nanofibers to cement hydrates benefited their reinforcement efficiency in UHPC.
\end{abstract}

\section{Introduction}

Ultrahigh performance concrete (UHPC) is an emerging class of cementitious composites with outstanding material properties [1-4]. UHPC offers very high strength (compressive strength $>150 \mathrm{MPa}$, tensile strength $>8 \mathrm{MPa})[2,5,6]$, toughness [3], and impact resistance [7]. UHPC exhibits strain-hardening behavior in tension [8] and provides ductile failure modes with desired postcracking tensile resistance. The extremely low permeability of the dense matrix $[2,9$, 10] provides UHPC with excellent durability characteristics. The distinct balance of qualities offered by UHPC are made possible by the use of a high content of cementitious binder (more than three times that of conventional concrete) $[11,12]$ with a very low water/binder ratio (less than 0.25$)[5,13,14]$, dense particle packing through proper grading of (relatively fine) aggregates, cement and supplementary cementitious materials [6], effective use of pozzolanic reactions [15] to refine the pore system and enhance the binding qualities of cement hydrates, and use of relatively high fiber contents to overcome the extreme brittleness of the ultrahigh strength cementitious matrix $[1,11,16,17]$.

UHPC has been used on a limited basis in the united Stated since $2000[13,18,19]$. Steel fibers are commonly used in UHPC. The high bonding qualities of UHPC enable effective use of fibers towards enhancement of engineering properties. The high binder content of UHPC also facilitates through dispersion of fibers, which further enhance their reinforcement efficiency [20]. The relatively large spacing of fibers (at viable volume fraction), however, makes the effective in control of the inception and initial growth of microcracks. Fibers are thus more effective in enhancing 
the postcracking behavior (toughness, ductility, and impact resistance) of concrete than its tensile/flexural strength and impermeability. These drawbacks of fibers could be resolved by the use of nanomaterials in fiber reinforced concrete.

The emergence of carbon nanotubes and lower-cost nanomaterials (e.g., carbon nanofiber) offers new opportunities for balanced improvement of concrete materials properties [20-24]. The close spacing of nanomaterials benefits their ability to hinder the formation and propagation of fine microcracks in concrete $[20,25-28]$. The distinct geometric attributes and mechanical characteristics of carbon nanotubes (CNTs) $[26,29-31]$ and carbon nanofibers (CNFs) $[20,26,32,33]$ could be used to complement the reinforcing effects of conventional fibers towards significant improvement of diverse concrete material properties.

Explanatory studies undertaken in recent years have demonstrated the value of graphite nanomatreials (CNTs and CNFs) in cementitious pastes $[25,31,34-36]$ as far as uniform dispersion and adequate interfacial bonding of nanomaterials are ensured $[20,33]$. Graphite nanomaterials improve the crack resistance of cementitious paste at relatively low volume fractions, while preserving acceptable fresh mix workability [14].

In UHPC, which relies upon a high packing density to realize distinct material properties, nanomaterials could further improve the packing density by extending the size distribution of particulate/fibrillar matter well into the nanoscale region.

When compared with CNTs, CNFs offer viable engineering and geometric attributes at substantially reduced cost; nanofiber surfaces are more amendable to functionalization and bonding than nanotube [37] Figure 1(a) shows near perfect praphene sheets on CNTs surfaces and Figure $1(\mathrm{~b})$ presents exposed edges of graphene located on CNFs surfaces.

An important challenge in effective use of nanomatreials in cementitious matrix is obtaining a uniform dispersion of nanomaterials within matrix $[21,33,38]$. Nanomaterials have a tendency to cluster via secondary (van der Waals) interactions between their high specific surface areas [21, 25]. In comparison with CNTs, CNFs provide surfaces with high concentrations of active sites for interaction with water molecules and also formation of bond with cement hydrates [39]. Dispersion of nanomaterials in cementitious pastes has been subject of few investigations [39].

The present study employs CNFs towards enhancement of UHPC material properties. The high compaction density and relatively fine capillary pore system of UHPC makes it a desirable cementitious matrix for evaluation of the contributions of CNFs to concrete material properties. CNF was and in combination with steel fiber (which is an inherent constituent of UHPC) focused and verifying the following hypotheses: (i) introduction of CNFs at very low dosages (compared to steel fibers) benefits interactions of steel fibers with cementitious matrix, thereby enabling reduction of the required steel fiber dosage and thus benefiting the fresh mix workability; and (ii) the nanoscale spacing and very large (compared to steel fibers) specific surface area and aspect ratio of CNFs allow them to effectively complement

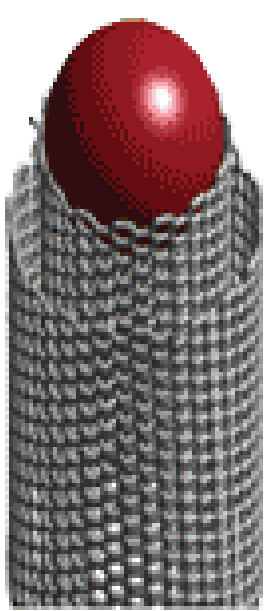

(a)

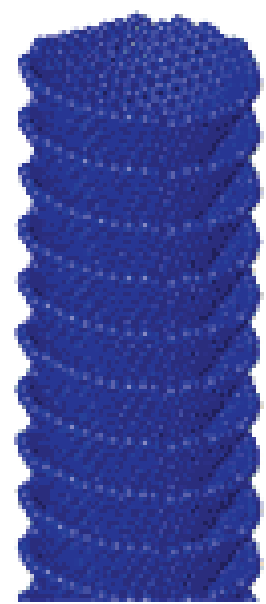

(b)
FIgURE 1: Schematic depiction of multiwalled carbon nanotube (a) and carbon nanofiber (b).

the reinforcing action of conventional (microscale) fibers in concrete.

An optimization experimental program was conducted in order to identify optimum dosages of CNF and steel fibers in UHPC. Effects of nanofiber surface modification on their performance in optimum UHPC nanocomposites were also investigated.

\section{Experimental Program}

2.1. Materials. The materials used for preparation of UHPC mixtures were Type I Portland cement, undensified silica fume (with $\sim 200 \mathrm{~nm}$ mean particle size, $\sim 15 \mathrm{~m}^{2} / \mathrm{g}$ specific surface area, and $>105 \%$ 7-day pozzolanic activity index), polycarboxylate-based superplasticizer ADVA Cast 575 (W.R. Grace Co.), conforming to ASTM C494 Type F, designed to impart high workability without segregation tendencies, silica sand (>99.5 wt.\% $\mathrm{SiO} 2$, ball milled and sieved to two particle size categories: $0.1-0.18 \mathrm{~mm}$ and $0.18-$ $0.5 \mathrm{~mm}$ ), granite gravel (with $8 \mathrm{~mm}$ and $3.5 \mathrm{~mm}$ maximum and mean particle size, resp.), oxidized carbon nanofiber shown in Figure 2 (with $60-150 \mathrm{~nm}$ diameter, $40-100 \mu \mathrm{m}$ length, $50-60 \mathrm{~m}^{2} / \mathrm{g}$ specific surface area, $\sim 1.95 \mathrm{~g} / \mathrm{cm}^{3}$ true density, and $>95 \%$ purity) obtained from Applied Sciences, Inc. (brand name Pyrograf III Type PR24), and coppercoated steel fiber with $175 \mu \mathrm{m}$ diameter and $13 \mathrm{~mm}$ length (Figure 3). In this study all carbon nanofibers used were carboxylic acid functionalized (oxidized); this was designated as unmodified. Since the density of functional group was low oxidized nanofibers were further treated with PAA for better dispersion and stronger interfacial interactions with the cementitious matrix. Oxidized nanofibers further treated with PAA were designated as modified nanofiber. Figure 4 depicts SEM micrographs of a PAA modified CNF in cementitious matrix. The prevalence of CNF pullout was noted at fractured surfaces; further a uniform distribution of nanofibers within the cementitious paste was observed. 


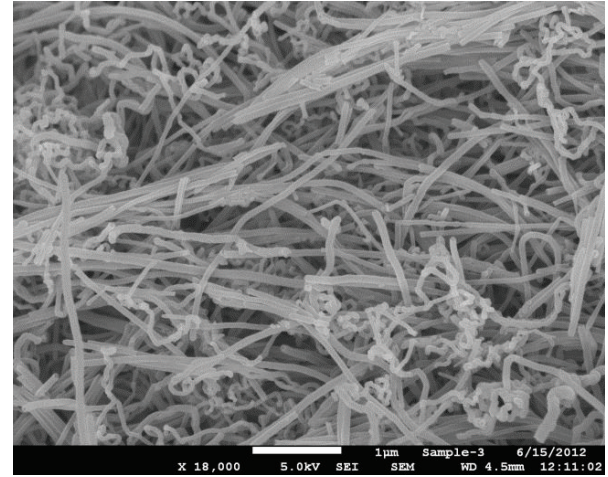

FIGURE 2: Scanning electron microscope image of oxidized carbon nanofiber.

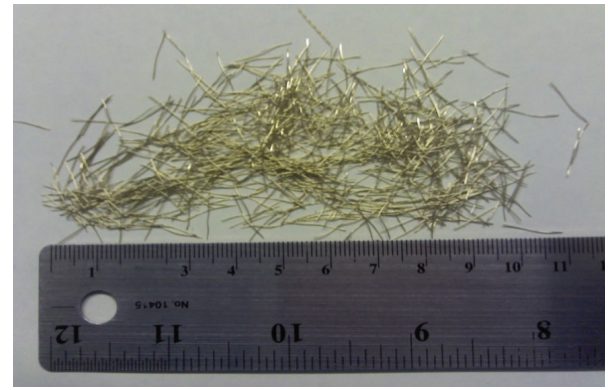

Figure 3: Copper-coated steel fiber.

TABLE 1: Ultrahigh performance concrete mix design.

\begin{tabular}{lc}
\hline Mix ingredient & Relative weight \\
\hline Cement (Type I) & 0.75 \\
Silica fume & 0.25 \\
Sand $(0-0.18 \mathrm{~mm})$ & 0.3 \\
Sand $(0.18-0.5 \mathrm{~mm})$ & 0.42 \\
Gravel $(\leq 8 \mathrm{~mm})$ & 0.42 \\
Water & 0.2 \\
Superplasticizer & 0.049
\end{tabular}

The UHPC mix design is presented in Table 1. The dosages of steel fiber and CNF in this concrete matrix were altered following the optimization experimental program described in the following section.

\subsection{Optimization Experimental Program. An optimization} experimental program was designed based on the response surface analysis principles, with the CNF and steel fiber dosage considered as the variables to be optimized. Based on authors past experience and cost consideration upper limits of $4 \%$ and $0.24 \%$ by volume of anhydrous cementitious materials were chosen for steel fiber and CNF, respectively. It should be noted that an optimization experimental program typically considers excursions beyond these assumed upper limits in order to test their viability. The optimization experimental program is summarized in Table 2; the volume fractions of nanofiber and steel fiber are presented as volume

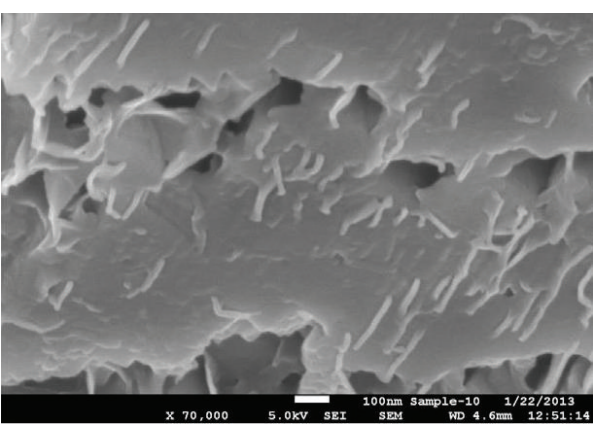

FIGURE 4: Scanning electron microscopy (SEM) image of the fractured surface on the nanocomposite showing uniform dispersion of modified CNF in the cementitious matrix.

fraction of concrete and anhydrous cementitious materials in Tables 2(a) and 2(b), respectively.

2.3. Carbon Nanofiber Surface Modification. Dispersion of CNFs in the mixing water of cementitious materials could benefit from modifications which render the CNF surfaces more hydrophilic. The surface modification techniques employed in this study emphasize introduction of hydrophilic groups on the edges of graphene sheets which form the peripheral surface of CNFs. These modifications render the CNF surfaces more hydrophilic facilitating their dispersion in aqueous media.

Polyacrylic acid (PAA), a polyelectrolyte with high density of $\mathrm{COOH}$ groups, was considered for adsorption upon (wrapping) CNFs in order to improve their dispersion in water and interaction with cement hydrates. For this purpose, CNFs were dispersed in water in the presence of PAA; different polymer-to-nanomaterial weight ratios were investigated and $0.1: 1.0$ was ratio found to be the most effective. PAA can, besides dispersing nanofibers in aqueous media by rendering CNF surfaces highly hydrophilic also effectively interact with the cementitious matrix by forming different secondary and primary bonds with calcium silicate hydrate $(\mathrm{C}-\mathrm{S}-\mathrm{H})$. PAA can be physisorbed upon (wrapped around) graphite nanomaterials. To accomplish this, nanomaterials were mixed with PAA in appropriate amount of water, and sonicated for 30 minutes. The resulting dispersion was exposed to microwave radiation for 10 minutes at $400 \mathrm{~W}$ and stirred overnight. It was sonicated again following the procedure described in the following section, with the amount of water adjusted to produce the required mixing water of concrete.

2.4. Carbon Nanofiber Dispersion Method. The procedures used for dispersion of CNF in the mixing water of concrete involved (i) adding the required amounts of oxidized nanofiber and PAA to water, and stirring for 12-15 hours, (ii) sonicateing the mix by repeating a cycle comprising (a) 10 minutes of sonication at $40,50,65$, and $75 \%$ of maximal power ( 400 watts) with 1-minute breaks in between, (b) pulsing (1 minute on, 30 seconds off) for $10 \mathrm{~min}$ at $80 \%$ of maximal power, and (c) repeating the previous (pulsing) step after 2 minutes of rest. 
TABLE 2: Volume percents with respect to anhydrous cementitious materials (concrete) of steel fiber and carbon nanofiber in the optimization experimental program.

(a) Volume fractions with respect to the volume of concrete

\begin{tabular}{|c|c|c|c|c|c|c|c|c|c|c|c|c|c|}
\hline & 1 & 2 & 3 & 4 & 5 & 6 & 7 & 8 & 9 & 10 & 11 & 12 & 13 \\
\hline Carbon nanofiber & 00.00 & 0.04 & 0.04 & 0.04 & 0.04 & 0.08 & 0.08 & 0.10 & 0.97 & 0.00 & 0.00 & 0.00 & 0.00 \\
\hline Steel fiber & 0.0 & 0.0 & 0.3 & 0.6 & 1.4 & 0.0 & 1.2 & 1.0 & 0.6 & 0.3 & 0.6 & 0.9 & 1.2 \\
\hline
\end{tabular}

(b) Volume fractions with respect to the volume of anhydrous cementitious materials

\begin{tabular}{|c|c|c|c|c|c|c|c|c|c|c|c|c|c|}
\hline & 1 & 2 & 3 & 4 & 5 & 6 & 7 & 8 & 9 & 10 & 11 & 12 & 13 \\
\hline Carbon nanofiber & 0.00 & 0.12 & 0.12 & 0.12 & 0.12 & 0.24 & 0.24 & 0.29 & 0.29 & 0.00 & 0.00 & 0.00 & 0.00 \\
\hline Steel fiber & 0.0 & 0.0 & 1.0 & 2.0 & 4.8 & 0.0 & 4.0 & 1.0 & 2.0 & 1.0 & 2.0 & 3.0 & 4.0 \\
\hline
\end{tabular}

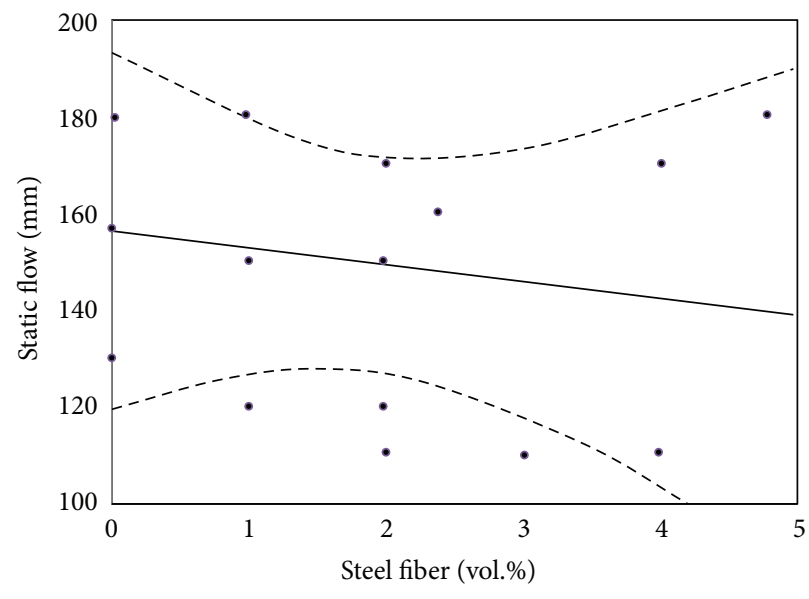

(a) Static flow

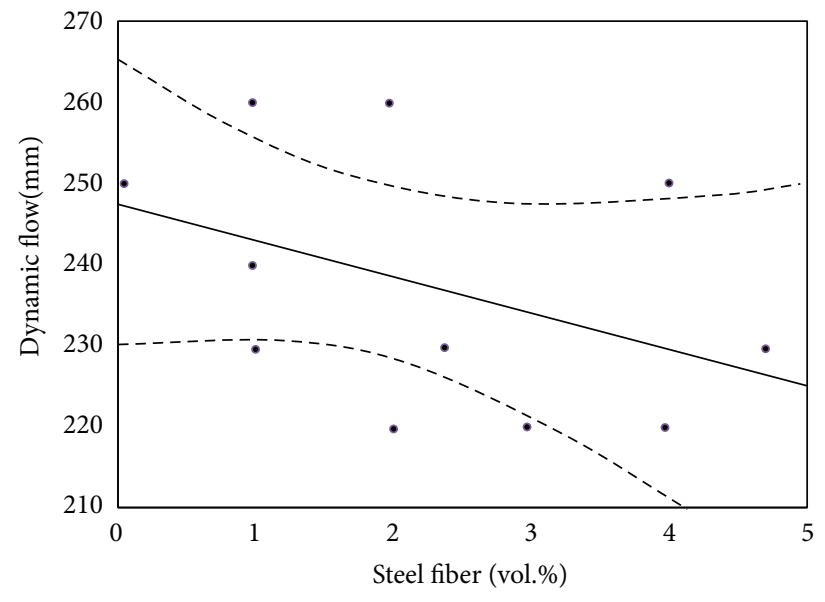

(b) Dynamic flow

FIGURE 5: Effects of steel fiber volume fraction (with respect to anhydrous cementitious materials) on the static and dynamic flow of fresh mix (regression lines and 95\% confidence intervals are shown; carbon nanofiber volume fraction varies).

2.5. Concrete Preparation. Following the dispersion of carbon nanofibers in the mixing water of concrete, normal concrete mixing procedures (outlined in ASTM D192 and C305) were followed for preparation of UHPC nanocomposites. The approach to preparation of concrete mixtures and specimens involved: (i) mixing of dry ingredients (cement, silica fume, sand, gravel) for 5 minutes in a mixer (Hobard Model A200F) at low Speed; (ii) addition of water (with dispersed nanomaterials), and mixing for 1 minute at low speed, 2 minutes at medium speed, and (while adding steel fibers) 2 minutes at high speed; and (iii) casting of concrete into molds per ASTM C192, and consolidating the molded concrete using a vibration table (FMC Syntron Power Plus) at high intensity. Specimens were moist-cured inside molds (per ASTM C192) at room temperature for 20 hours after casting, and were then demolded and subjected to 48 hours of steam curing at $70^{\circ} \mathrm{C}$. The specimens were then conditioned at $50 \%$ relative humidity and ambient temperature for 7 days prior to testing.

2.6. Test Methods. Workability of fresh concrete mixtures was assessed using static and dynamic flow table tests (ASTM C230). Hardened concrete materials were subjected to (i) three-point flexure tests (ASTM C78) on $150 \times 50 \times 12.5 \mathrm{~mm}$ prismatic specimens; (ii) impact tests (ASTM D7136) on $150 \mathrm{~mm}$ square plates specimens with thickness of $12 \mathrm{~mm}$, (iii) abrasion tests (ASTM C944) on cylindrical specimens with $150 \mathrm{~mm}$ diameter and $12 \mathrm{~mm}$ length; and (iv) compression tests (ASTM C109) on $50 \mathrm{~mm}$ cubic samples. These replicated specimens were subjected to each of these tests.

2.7. Experimental Results and Discussion. The trends in fresh mix static and dynamic flow test results (representing fresh mix workability) at different steel fiber and (unmodified) CNF volume fractions (with respect to anhydrous cementitious materials) are presented in Figures 5 and 6, respectively. Figure 5 shows some minor (anticipated) loss of flow with increasing volume fraction of steel fibers (for different nanofiber volume fractions). Figure 6, however, shows a minor (unexpected) rise in flow (i.e., gain in fresh mix workability) with increasing nanofiber volume fraction (at different steel fiber contents). This is unexpected because the high specific surface area of nanofibers is expected to adsorb a fraction of mixing water, thus lowering fresh mix workability. The gain in fresh mix workability could have resulted from the rise in packing density of concrete in 


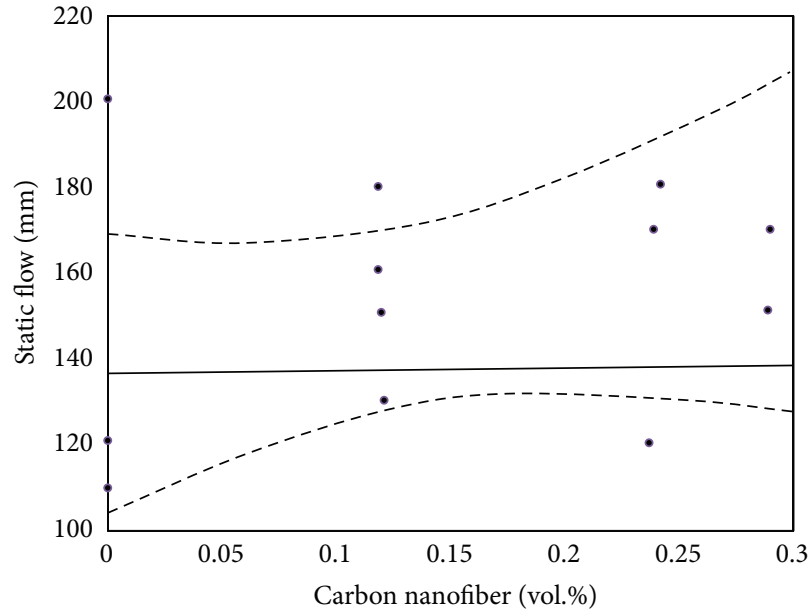

(a) Static flow

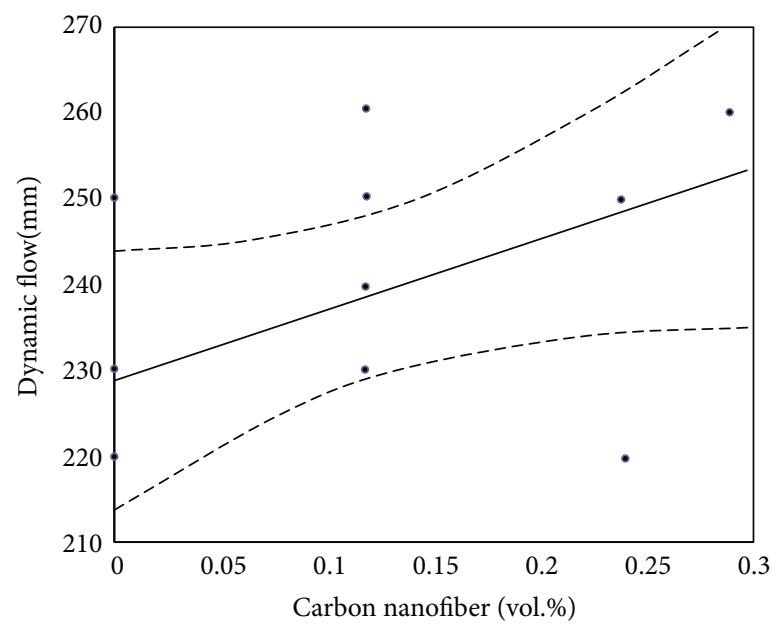

(b) Dynamic flow

Figure 6: Effects of carbon nanofiber volume fraction (with respect to anhydrous cementitious materials) on the static and dynamic flow of fresh mix (regression lines and 95\% confidence intervals are shown; steel fiber volume fraction varies).

the presence of nanomaterials, which enables more effective use of water (with superplasticizer) towards lubricating the particulate matter. Rolling of nanofibers against particulate matter and the highly hydrophilic nature of the modified nanofiber surfaces could also benefit fresh mix workability.

The flexural strength, maximum deflection and energy absorption capacity (obtained from flexural test results), impact resistance, abrasion weight loss, and compressive strength test results are presented in Figure 7. It should be noted that the experimental results of Figure 7 were produced with unmodified carbon nanofiber. Response surface plots based on these test data, which show the trends in effects of steel fiber and CNF volume fractions on different material properties, are presented in Figure 8. Synergistic actions of steel fibers and CNFs towards improvement of the flexural strength, impact resistance, and abrasion weight loss can be observed in the response surface plots presented in Figures $8(\mathrm{a}), 8(\mathrm{~d})$, and $8(\mathrm{e})$, respectively, where peaks (or valley in the case of abrasion weight loss) are reached with a hybrid reinforcement comprising a moderate volume fraction of steel fiber and a relatively low volume fraction of CNF. Similar (but weaker) synergistic actions can be observed for the maximum deflection and compressive strength test data presented in Figures 8(b) and 8(f), respectively.

Desirability (canonical) analysis of experimental results was conducted in order to determine the optimum combination of steel fiber and CNF for achieving balanced gains in UHPC. All properties were given similar weight and importance factors in the optimization process. The optimization response surface analysis used the mean values of experimental results as input and sought to identify the reinforcement condition which simultaneously maximizes flexural strength (21.7 MPa target value), maximum deflection (27.9 $\mathrm{mm}$ target value), energy absorption capacity (4800 N.mm target value), impact resistance $(6.68 \mathrm{~mm} / \mathrm{mm}$ target value), and compressive strength (170 MPa target value) and minimizes abrasion weight loss ( $0.085 \mathrm{~g}$ target value). Outcomes of this optimization process indicated that an optimum hybrid reinforcement system comprises CNF at $0.145 \mathrm{vol} \%$ of anhydrous cementitious materials ( $0.04 \mathrm{vol} . \%$ of concrete) and steel fiber at 3.55 vol. $\%$ of anhydrous cementitious materials (1.1 vol.\% of concrete). This optimum reinforcement system is projected to yield mean flexural strength, maximum deflection, energy absorption capacity, impact resistance, abrasion weight loss, and compressive strength values of $19.6 \mathrm{MPa}, 26.6 \mathrm{~mm}, 4900$ $\mathrm{N} \cdot \mathrm{mm}, 6.68 \mathrm{~mm} / \mathrm{mm}, 0.085 \mathrm{~g}$ and $143 \mathrm{MPa}$, respectively. The fact that the optimized system comprises both steel fiber and CNF points at their synergistic actions towards enhancement of the UHPC material properties is considered here.

\subsection{Characterization of Optimum UHPC Nanocomposite with} Unmodified and Modified Carbon Nanofibers. UHPC materials were prepared with the optimum combination of steel fiber and CNF dosages identified above and were characterized using the experimental methods introduced earlier. While the tests data presented above were produced using unmodified (oxidized) CNFs, optimum systems were produced with unmodified and also with PAA-modified (oxidized) CNFs, noting that PAA modification, introduced earlier, was found to benefit the efficiency of CNF performance in cementitious materials (by improving their dispersion and interfacial interactions). As described earlier, PAA was introduced together with CNFs (at PAA : nanofiber weight ratio of $0.1: 1)$ to the mixing water of concrete prior to reinforcing the nanofiber dispersion process. Table 3 compares the mean values of flexural strength, maximum deflection, energy absorption capacity, impact resistance, abrasion weight loss, and compressive strength of UHPC materials with and without PAA modification of CNFs as well as the corresponding mean values of plain UHPC and with a UHPC relatively high steel fiber content ( 2 vol.\% of anhydrous cementitious materials). The experimental results summarized in Table 3 indicate 


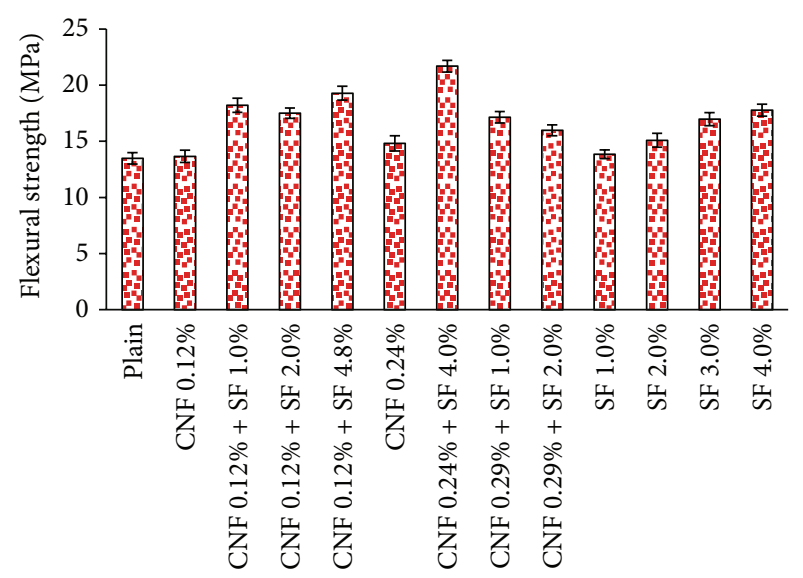

(a) Flexural strength

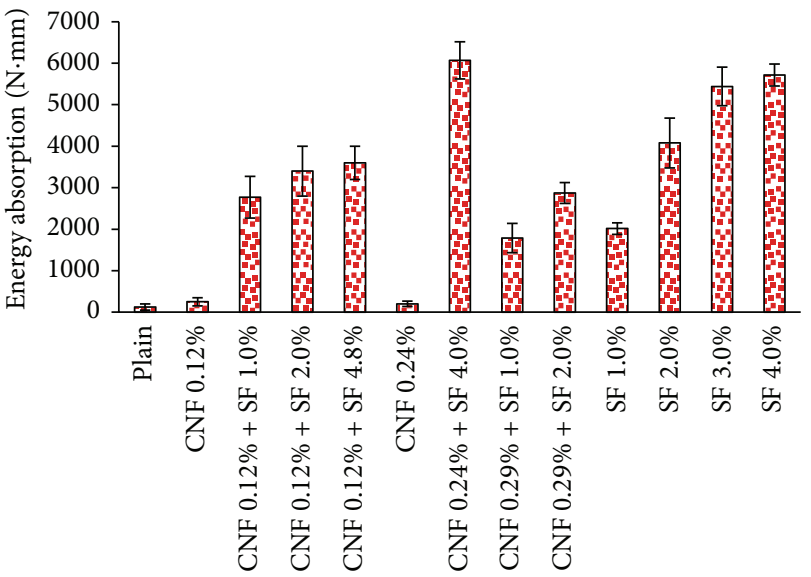

(c) Energy absorption capacity

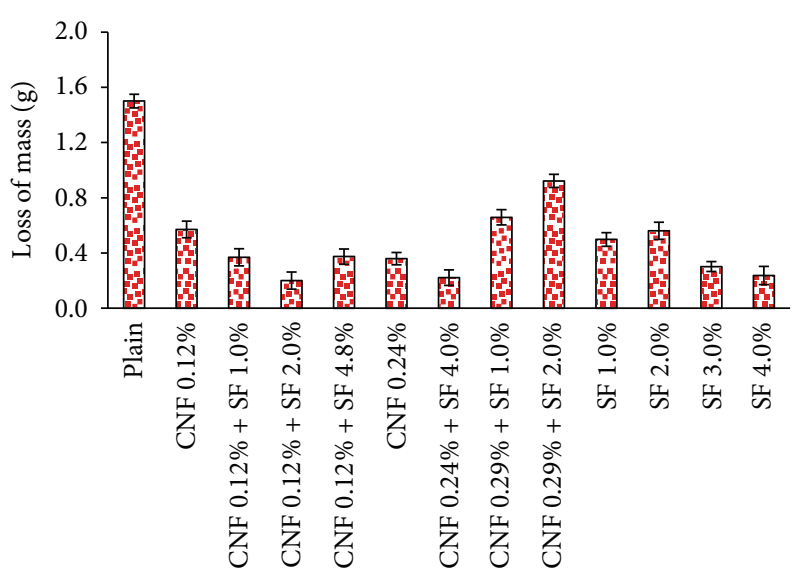

(e) Abrasion weight loss

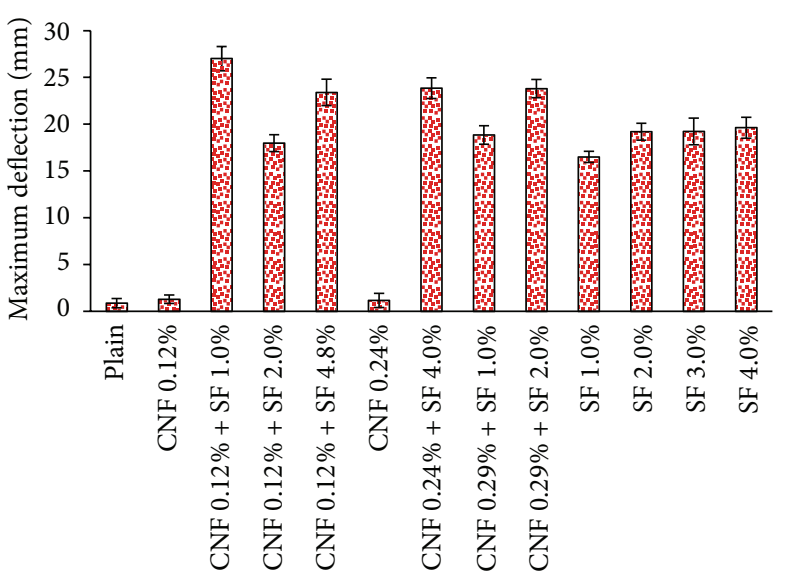

(b) Maximum deflection

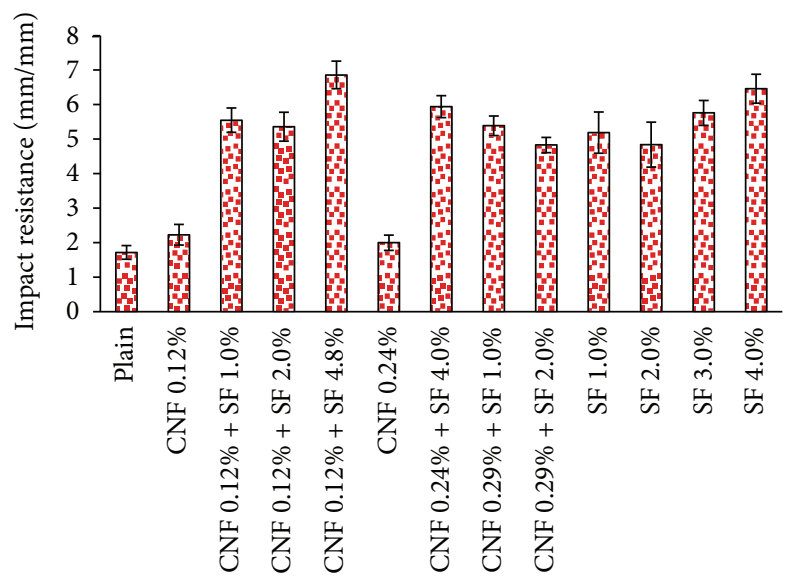

(d) Impact resistance

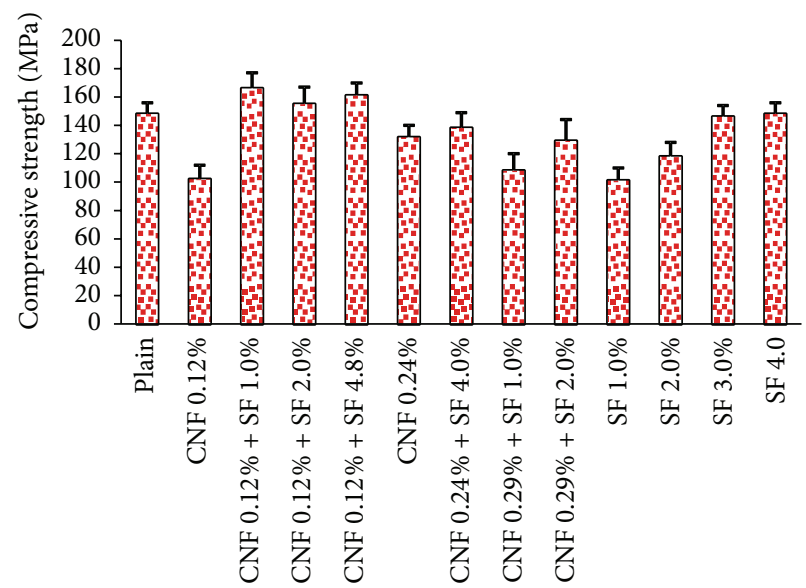

(f) Compressive strength

FIGURE 7: Experimental results on hardened ultrahigh performance concrete material properties (CNF: carbon nanofiber, SF: steel fiber) (means \& standard errors).

that (i) the optimum reinforcement system comprising a moderate dosage of steel fiber and a relatively low volume fraction of CNFs produces major gains in diverse UHPC material properties; (ii) PAA modification of CNFs further improves the performance characteristics of UHPC with optimum reinforcement system; and (iii) use of steel fiber at a relatively high volume fraction cannot produce the balanced gains in diverse engineering properties of UHPC enabled by the use of a moderate steel fiber content together with a relatively low CNF content (noting that high steel fiber contents 


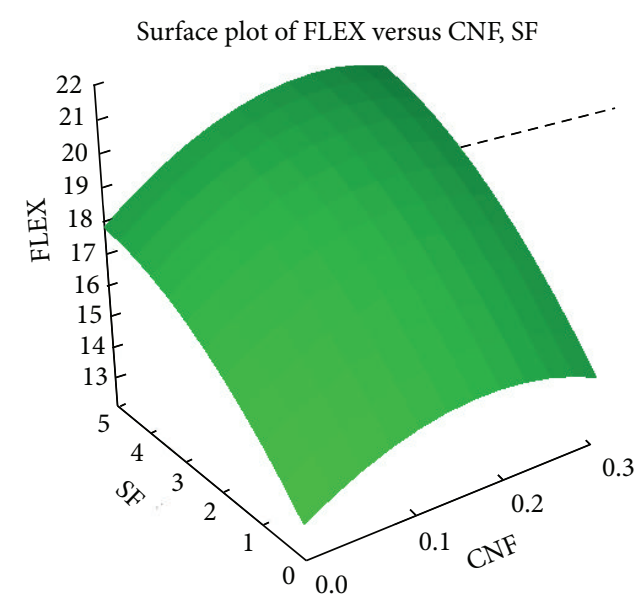

(a) Flexural strength, MPa

Surface plot of ACE versus CNF, SF

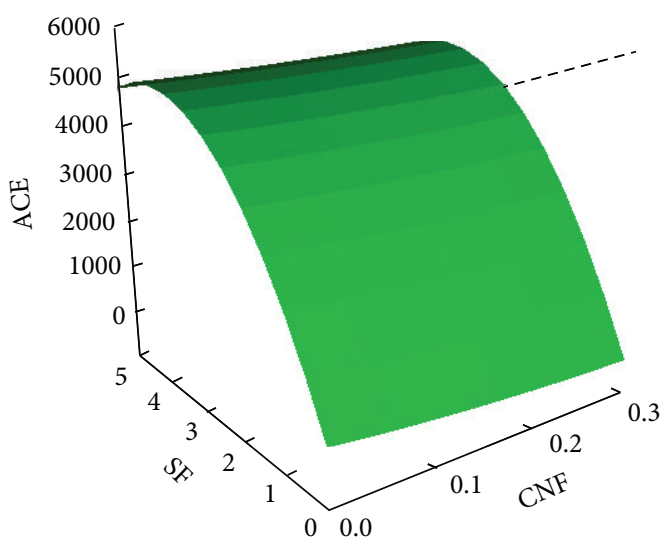

(c) Energy absorption capacity, N.mm

Surface plot of ABRA versus CNF, SF

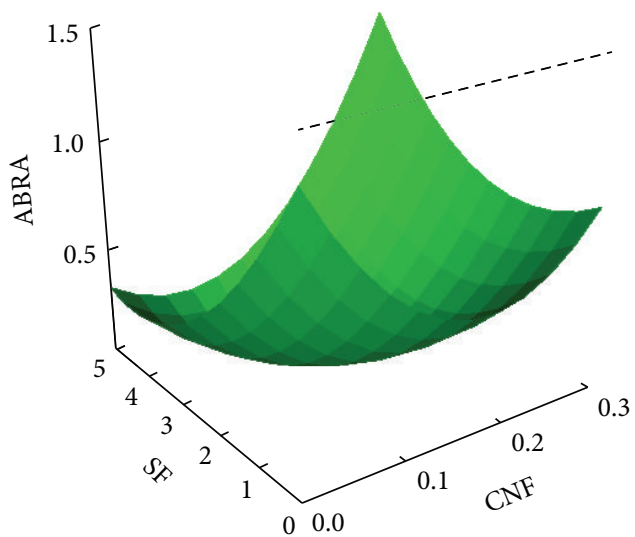

(e) Abrasion weight loss, g
Surface plot of DEFL versus CNF, SF

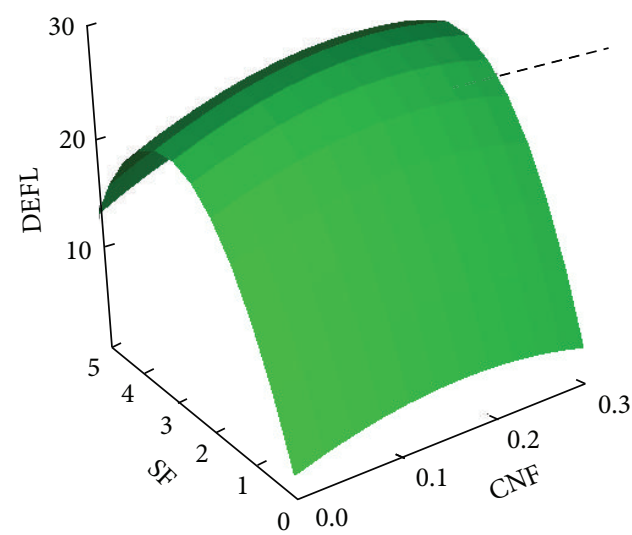

(b) Maximum deflection, $\mathrm{mm}$

Surface plot of IMPACT versus CNF, SF

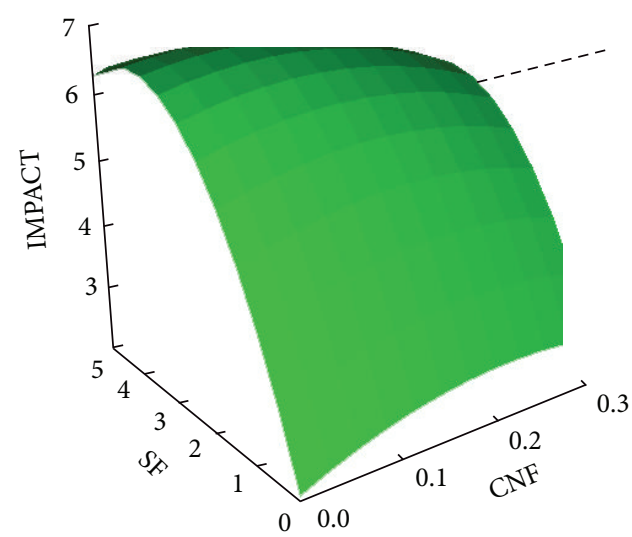

(d) Impact resistance, $\mathrm{mm} / \mathrm{mm}$

Surface plot of COMP versus CNF, SF

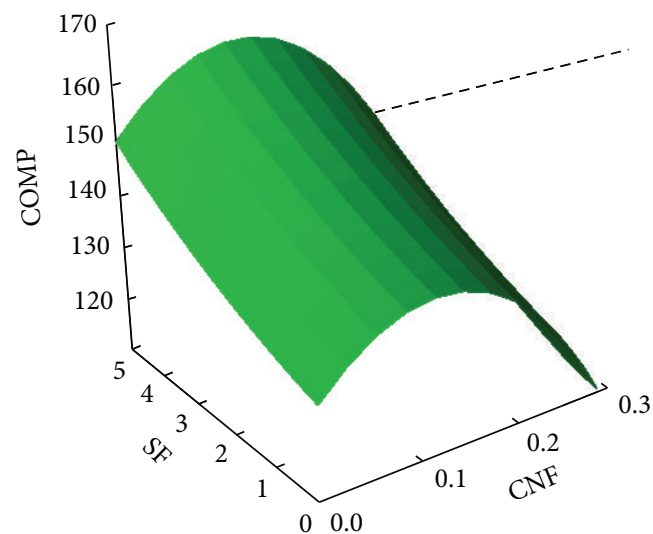

(f) Compressive strength, $\mathrm{MPa}$

FIGURE 8: Response surfaces developed using the experimental results (CNF: carbon nanofiber, SF: steel fiber).

negatively impact the fresh mix workability and economics of UHPC). The optimum combination of steel fiber with PAAmodified CNF brings about 50\%, 240\%, 2700\%, 236\%, 1200\%, and $5 \%$ improvements in the flexural strength, maximum deflection, energy absorption capacity, impact resistance, abrasion resistance, and compressive strength of (plain) UHPC, respectively. The corresponding improvements over material properties of UHPC with relatively high steel fiber volume fraction are $34 \%, 54 \%,-4 \%, 18 \%, 400 \%$, and $34 \%$, respectively. These findings point at the high value rendered 
TABLE 3: Mean values of material properties for plain and optimally reinforced ultrahigh performance concrete (UHPC) materials and UHPC with a relatively high steel fiber content.

\begin{tabular}{|c|c|c|c|c|c|c|}
\hline UHPC type & $\begin{array}{c}\text { Flexural } \\
\text { strength, } \mathrm{MPa}\end{array}$ & $\begin{array}{c}\text { Maximum } \\
\text { deflection, } \mathrm{mm}\end{array}$ & $\begin{array}{c}\text { Energy } \\
\text { absorption } \\
\text { capacity, } \mathrm{N} \cdot \mathrm{mm}\end{array}$ & $\begin{array}{c}\text { Impact } \\
\text { resistance, } \\
\mathrm{mm} / \mathrm{mm}\end{array}$ & $\begin{array}{c}\text { Abrasion weight } \\
\text { loss, g }\end{array}$ & $\begin{array}{l}\text { Compressive } \\
\text { strength, } \mathrm{MPa}\end{array}$ \\
\hline Plain & 13.4 & 1.2 & 140.0 & 1.8 & 1.5 & 151.0 \\
\hline High steel fiber content & 15.0 & 19.0 & 4106.0 & 5.0 & 0.6 & 119.0 \\
\hline Optimum, CNF & 19.4 & 24.4 & 3669.0 & 5.4 & 0.2 & 152.0 \\
\hline Optimum, PAA-CNF & 20.1 & 29.2 & 3925.0 & 5.9 & 0.1 & 159.0 \\
\hline
\end{tabular}

by modified CNF towards enhanced of (fiber reinforced) UHPC material properties.

The experimental results and analyses presented above point at synergistic and complementary effects of CNF and steel fiber in concrete. These effects could be attributed to (i) reinforcing effects of CNF and steel fiber at different scales, with nanofiber primarily mitigating formation and propagation of microcracks, and steel fiber mainly hindering growth and opening of larger cracks; (ii) beneficial effects of CNFs on the pull-out behavior of steel fibers from concrete; and (iii) nanoscale spacing of CNFs in concrete, which significantly benefits the barrier and durability characteristics as well as the abrasion resistance of concrete.

\section{Conclusions}

In development of ultrahigh performance concrete (UHPC), one important consideration in size gradation of the particulate (and fibrous) matter in concrete for maximizing their packing density with due consideration given to the type and extent of the consolidation effort. Carbon nanofiber offers distinct features for effective reinforcement of cementitious matrices in the precrack and postcrack ranges of behavior. In this investigation, a comprehensive optimization experimental work was designed based on response surface analysis principles, and implemented for identifying optimum combinations of carbon nanofiber and steel fiber in ultrahigh performance concrete. It was found that hybrid system comprising unmodified carbon nanofiber at 0.145 vol. $\%$ of anhydrous cementitious materials ( 0.04 vol.\% of concrete) and steel fiber at $3.55 \mathrm{vol} . \%$ of anhydrous cementitious materials ( $1.1 \mathrm{vol} . \%$ of concrete) provided balanced gains in engineering properties of ultrahigh performance concrete. This optimum reinforcement system was used to evaluate the effects of nanofiber surface modification on UHPC material properties. The surface modification technique employed in the project emphasized introduction of hydrophilic groups on graphite nanomaterials in order to facilitate their dispersion in aqueous media. Polyacrylic acid (PAA) with high density of COOH groups, at 0.1 (PAA) : 1.0 (carbon nanofiber) weight ratio, was added to the mixing water prior to dispersion of nanofibers in order to introduce hydrophilic groups on the surfaces of carbon nanofibers.

Outcomes of the optimization experimental program indicated that (i) the optimum hybrid reinforcement system comprising a moderate dosage of steel fiber and a relatively low dosage of carbon nanofiber produced major gains in diverse material properties of ultrahigh performance concrete; (ii) introduction of hydrophilic groups on the grapheme edges comprising the peripheral surfaces of carbon nanofibers improved the performance characteristics of ultrahigh performance concrete with optimum reinforcement system; (iii) optimum hybrid (nano- and microscale) reinforcement system surpassed high volume fraction of micro-scale (steel) fiber in terms of hardened material engineering properties and fresh mix workability. The optimum combination of steel fiber with PAA-modified carbon nanofiber produced 50\%, 240\%, 2700\%, 236\%, 1200\%, and $5 \%$ improvements in the flexural strength, maximum deflection, energy absorption capacity, impact resistance, abrasion resistance, and compressive strength of (plain) UHPC, respectively. The corresponding improvements over material properties of ultrahigh performance concrete with a relatively high steel fiber volume fraction were $34 \%, 54 \%$, $-4 \%, 18 \%, 400 \%$, and $34 \%$, respectively.

\section{Conflict of Interests}

The authors declare that there is no conflict of interests regarding the publication of this paper.

\section{Acknowledgment}

The authors wish to acknowledge the financial support of National Science Foundation (NSF), Grant no. IIP-1142455 for the project report herein.

\section{References}

[1] V. Corinaldesi and G. Moriconi, "Mechanical and thermal evaluation of Ultra High Performance Fiber Reinforced Concretes for engineering applications," Construction and Building Materials, vol. 26, no. 1, pp. 289-294, 2012.

[2] K. Habel, M. Viviani, E. Denarié, and E. Brühwiler, "Development of the mechanical properties of an Ultra-High Performance Fiber Reinforced Concrete (UHPFRC)," Cement and Concrete Research, vol. 36, no. 7, pp. 1362-1370, 2006.

[3] J. Lai and W. Sun, "Dynamic mechanical behaviour of ultrahigh performance fiber reinforced concretes," Journal Wuhan University of Technology-Materials, vol. 23, no. 6, pp. 938-945, 2008.

[4] N. Yi, J. J. Kim, T. Han, Y. Cho, and J. H. Lee, "Blast-resistant characteristics of ultra-high strength concrete and reactive 
powder concrete," Construction and Building Materials, vol. 28, no. 1, pp. 694-707, 2012.

[5] N. van Tuan, G. Ye, K. van Breugel, and O. Copuroglu, "Hydration and microstructure of ultra high performance concrete incorporating rice husk ash," Cement and Concrete Research, vol. 41, no. 11, pp. 1104-1111, 2011.

[6] K. Wille, A. E. Naaman, S. El-Tawil, and G. J. Parra-Montesinos, "Ultra-high performance concrete and fiber reinforced concrete: achieving strength and ductility without heat curing," Materials and Structures, vol. 45, no. 3, pp. 309-324, 2012.

[7] . Lai J, W. Sun, S. Xu, and C. Yang, "Dynamic properties and damage model of ultra-high performance fiber reinforced cement composites subjected to repeated impacts," in High Performance Fiber Reinforced Cement Composites 6, vol. 2 of RILEM State of the Art Reports, pp. 389-396, Springer Science+Business Media B.V., Amsterdam, The Netherlands, 2012.

[8] K. Kobayashi, T. Iizuka, H. Kurachi, and K. Rokugo, "Corrosion protection performance of High Performance Fiber Reinforced Cement Composites as a repair material," Cement and Concrete Composites, vol. 32, no. 6, pp. 411-420, 2010.

[9] S. Michael and F. Ekkehard, "Ultra-high-performance concrete: research, development and application in Europe," in Proceedings of the 7th internatinal symposium on the utilization of (UHS/HPC '05), pp. 51-77, 2005.

[10] E. Vejmelková, M. Pavlíková, Z. Keršner et al., "High performance concrete containing lower slag amount: a complex view of mechanical and durability properties," Construction and Building Materials, vol. 23, no. 6, pp. 2237-2245, 2009.

[11] S. J. Barnett, J. Lataste, T. Parry, S. G. Millard, and M. N. Soutsos, "Assessment of fibre orientation in ultra high performance fibre reinforced concrete and its effect on flexural strength," Materials and Structures, vol. 43, no. 7, pp. 1009-1023, 2010.

[12] P. Rossi, A. Arca, E. Parant, and P. Fakhri, "Bending and compressive behaviours of a new cement composite," Cement and Concrete Research, vol. 35, no. 1, pp. 27-33, 2005.

[13] FHWA, "Ultra-high performance concrete," Tech. Rep. FHWAHRT-11-038, Office of Research, Development, and Technology, Turner-Fairbank Highway Research Center, McLean, Va, USA, 2011.

[14] K. Wille and K. J. Loh, "Nanoengineering ultra-highperformance concrete with multiwalled carbon nanotubes," Transportation Research Record, no. 2142, pp. 119-126, 2010.

[15] C. Schröfl, M. Gruber, and J. Plank, "Preferential adsorption of polycarboxylate superplasticizers on cement and silica fume in ultra-high performance concrete (UHPC)," Cement and Concrete Research, vol. 42, no. 11, pp. 1401-1408, 2012.

[16] R. Deeb, A. Ghanbari, and B. L. Karihaloo, "Development of self-compacting high and ultra high performance concretes with and without steel fibres," Cement and Concrete Composites, vol. 34, no. 2, pp. 185-190, 2012.

[17] S. Kang and J. Kim, “The relation between fiber orientation and tensile behavior in an ultra high performance fiber reinforced cementitious composites (UHPFRCC)," Cement and Concrete Research, vol. 41, no. 10, pp. 1001-1014, 2011.

[18] Y. L. Voo, P. C. Augustin, and T. A. J. Thamboe, "Construction and design of a $50 \mathrm{~m}$ single span uhp ductile concrete composite road bridge," Structural Engineer, vol. 89, no. 15-16, pp. 24-31, 2011.

[19] I. Yang, C. Joh, and B. Kim, "Flexural strength of largescale ultra high performance concrete prestressed T-beams,"
Canadian Journal of Civil Engineering, vol. 38, no. 11, pp. 11851195, 2011.

[20] Z. S. Metaxa, M. S. Konsta-Gdoutos, and S. P. Shah, "Carbon nanofiber-reinforced cement-based materials," Transportation Research Record, no. 2142, pp. 114-118, 2010.

[21] C. Gay and F. Sanchez, "Performance of carbon nanofibercement composites with a high-range water reducer," Transportation Research Record, no. 2142, pp. 109-113, 2010.

[22] S. Wansom, N. J. Kidner, L. Y. Woo, and T. O. Mason, "ACimpedance response of multi-walled carbon nanotube/cement composites," Cement and Concrete Composites, vol. 28, no. 6, pp. 509-519, 2006.

[23] A. Peyvandi, P. Soroushian, A. M. Balachandra, and K. Sobolev, "Enhancement of the durability characteristics of concrete nanocomposite pipes with modified graphite nanoplatelets," Construction and Building Materials, vol. 47, pp. 111-117, 2013.

[24] A. Peyvandi and P. Soroushian, "Structural performance of drycast concrete nanocomposite pipes," Materials and Structures, 2013.

[25] M. S. Konsta-Gdoutos, Z. S. Metaxa, and S. P. Shah, "Multiscale mechanical and fracture characteristics and early-age strain capacity of high performance carbon nanotube/cement nanocomposites," Cement and Concrete Composites, vol. 32, no. 2, pp. 110-115, 2010.

[26] B. M. Tyson, R. K. Abu Al-Rub, A. Yazdanbakhsh, and Z. Grasley, "Carbon nanotubes and carbon nanofibers for enhancing the mechanical properties of nanocomposite cementitious materials," Journal of Materials in Civil Engineering, vol. 23, no. 7, pp. 1028-1035, 2011.

[27] A. Peyvandi, P. Soroushian, N. Abdol, and A. M. Balachandra, "Surface-modified graphite nanomaterials for improved reinforcement efficiency in cementitious paste," Carbon, vol. 63, pp. 175-186, 2013.

[28] G. Z. Voyiadjis and N. Mozaffari, "Nonlocal damage model using the phase field method: theory and applications," International Journal of Solids and Structures, vol. 50, no. 20-21, pp. 3136-3151, 2013.

[29] L. Y. Chan and B. Andrawes, "Characterization of the uncertainties in the constitutive behavior of carbon nanotube/cement composites," Science and Technology of Advanced Materials, vol. 10, no. 4, Article ID 045007, 2009.

[30] Z. S. Metaxa, M. S. Konsta-Gdoutos, and S. P. Shah, "Carbon nanotubes reinforced concrete," in Proceedings of the ACI Fall Convention, pp. 11-20, American Concrete Institute, New Orleans, La, USA, 2009.

[31] S. Musso, J. Tulliani, G. Ferro, and A. Tagliaferro, "Influence of carbon nanotubes structure on the mechanical behavior of cement composites," Composites Science and Technology, vol. 69, no. 11-12, pp. 1985-1990, 2009.

[32] R. K. Abu Al-Rub, B. M. Tyson, A. Yazdanbakhsh, and Z. Grasley, "Mechanical properties of nanocomposite cement incorporating surface-treated and untreated carbon nanotubes and carbon nanofibers," Journal of Nanomechanics and Micromechanics, vol. 2, no. 1, pp. 1-6, 2012.

[33] Z. S. Metaxa, J. T. Seo, M. S. Konsta-Gdoutos, M. C. Hersam, and S. P. Shah, "Highly concentrated carbon nanotube admixture for nano-fiber reinforced cementitious materials," Cement and Concrete Composites, vol. 34, no. 5, pp. 612-617, 2012.

[34] M. S. Konsta-Gdoutos, Z. S. Metaxa, and S. P. Shah, "Highly dispersed carbon nanotube reinforced cement based materials," Cement and Concrete Research, vol. 40, no. 7, pp. 1052-1059, 2010. 
[35] G. Y. Li, P. M. Wang, and X. Zhao, "Pressure-sensitive properties and microstructure of carbon nanotube reinforced cement composites," Cement and Concrete Composites, vol. 29, no. 5, pp. 377-382, 2007.

[36] Z. S. Metaxa, M. S. Konsta-Gdoutos, and S. P. Shah, "Carbon nanotubes reinforced concrete," ACI Journal, vol. 267, pp. 11-20, 2009.

[37] O. Galao, E. Zornoza, F. J. Baeza, A. Bernabeu, and P. Garcés, "Effect of carbon nanofiber addition in the mechanical properties and durability of cementitious materials," Materiales de Construcción, vol. 62, no. 307, pp. 343-357, 2012.

[38] L. I. Nasibulina, I. V. Anoshkin, S. D. Shandakov et al., "Direct synthesis of carbon nanofibers on cement particles," Transportation Research Record, no. 2142, pp. 96-101, 2010.

[39] A. Cwirzen, K. Habermehl-Cwirzen, and V. Penttala, "Surface decoration of carbon nanotubes and mechanical properties of cement/carbon nanotube composites," Advances in Cement Research, vol. 20, no. 2, pp. 65-73, 2008. 

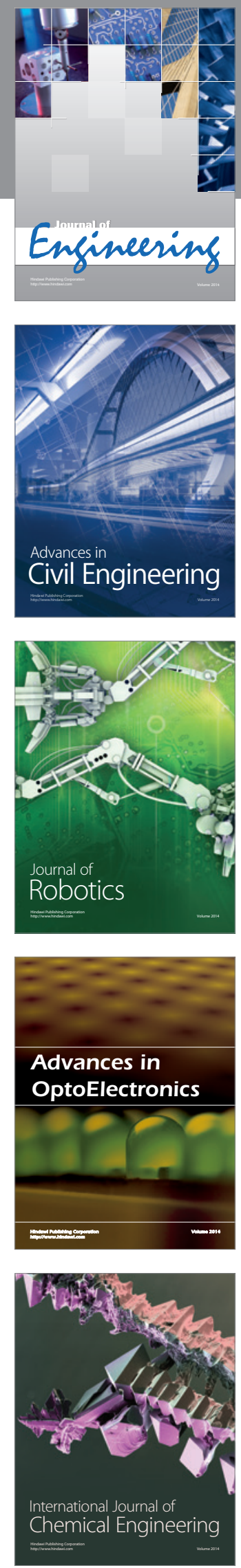

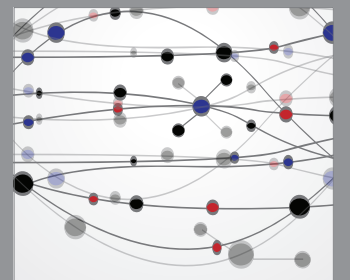

The Scientific World Journal
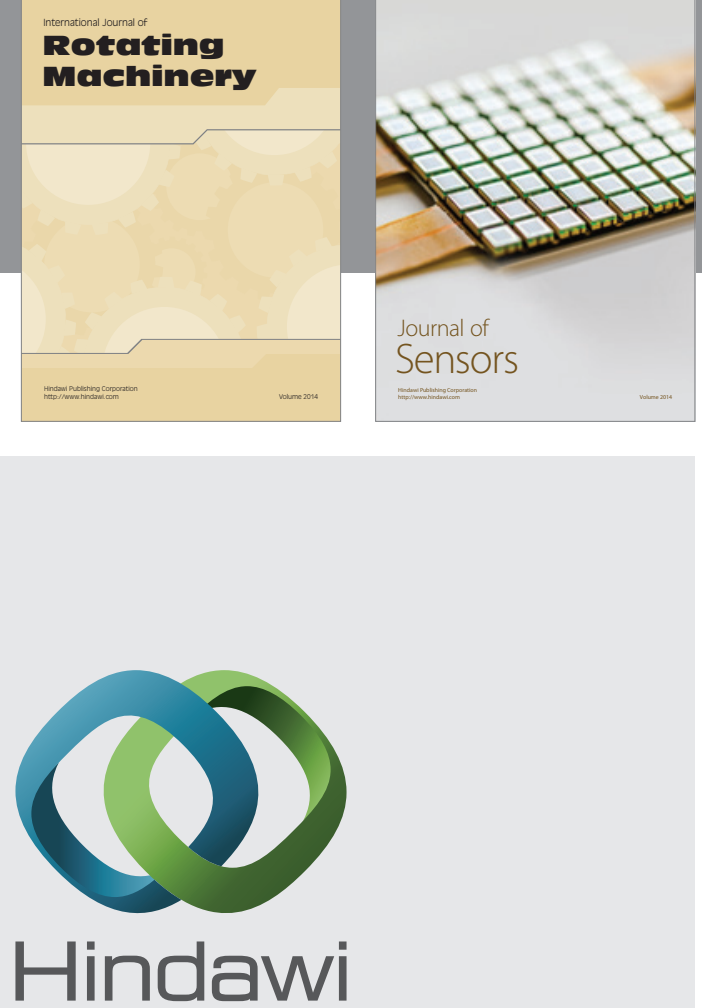

Submit your manuscripts at http://www.hindawi.com
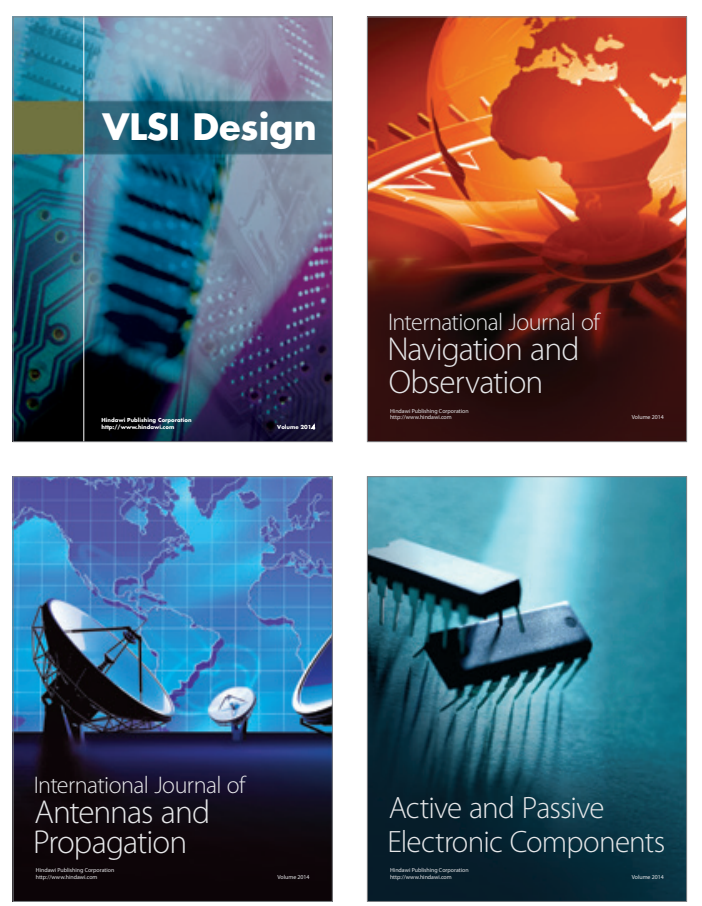
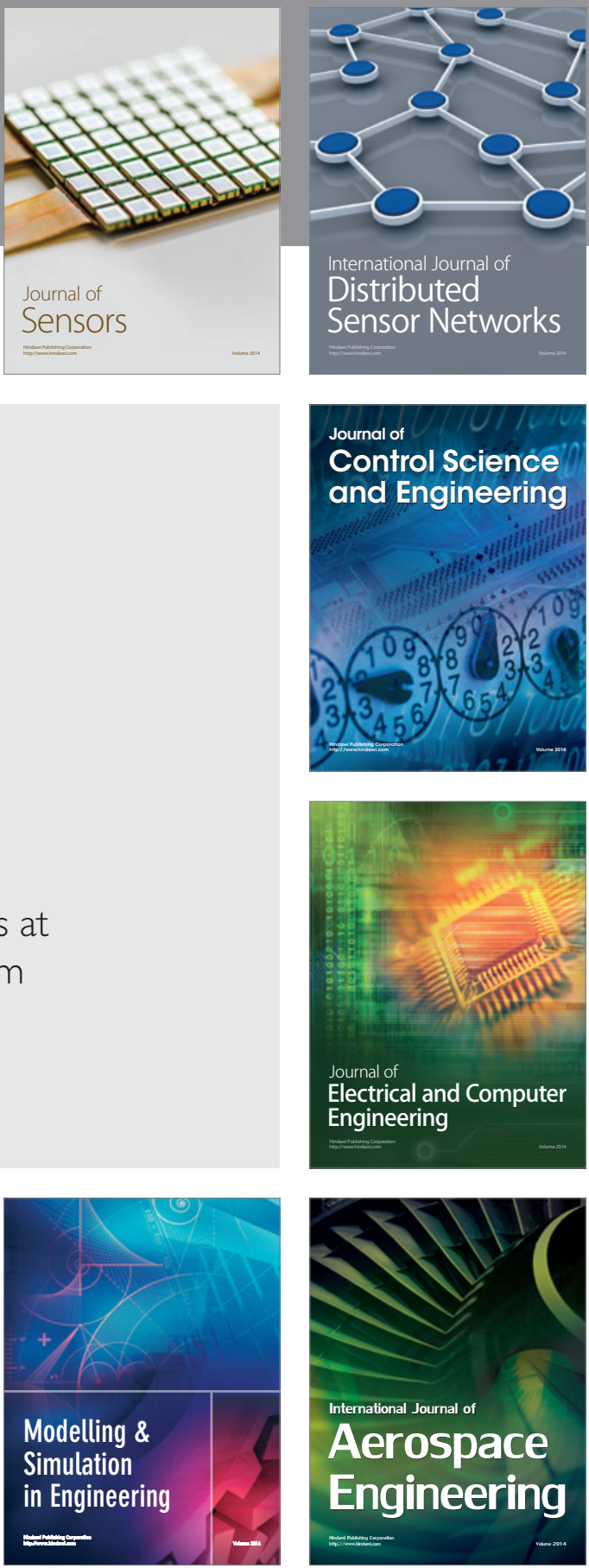

Journal of

Control Science

and Engineering
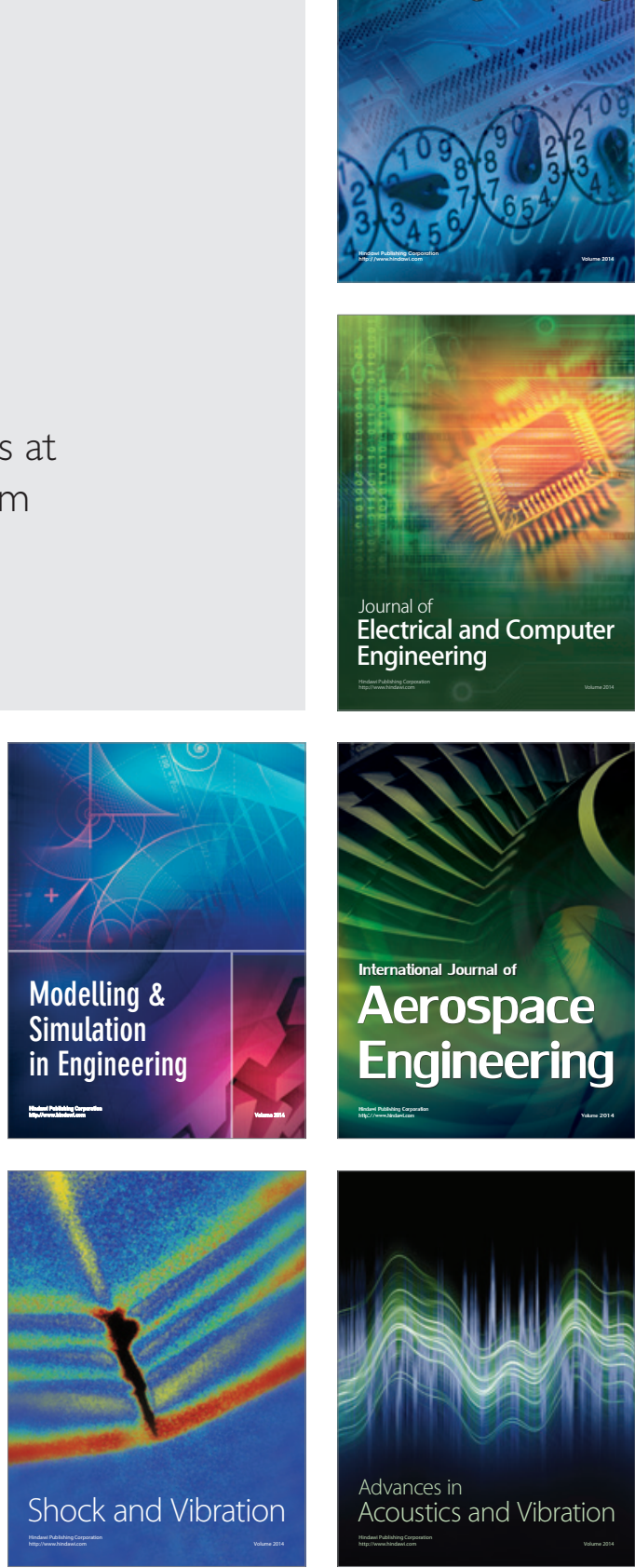